\title{
A Novel Design of an H-shaped Microstrip Diplexer
}

\author{
A. Chinig ${ }^{1}, \mathrm{H}$. Bennis ${ }^{2}$ \\ ${ }^{1}$ Faculty of Sciences and Techniques, Hassan First University, Settat-Morocco \\ abdo.chinig@gmail.com \\ ${ }^{2}$ TIM Research Team, EST of Meknes, Moulay Ismail University, Morocco \\ hamid.bennis@gmail.com
}

\begin{abstract}
In this paper, a new microstrip diplexer using modified H-shaped resonators with a compact size and high isolation is presented. This circuit is designed for the ISM band at $2.4 \mathrm{GHz}$ and GPS at $1.575 \mathrm{GHz}$. The proposed diplexer is formed by connecting two band-pass filters designed by using the modified H-shaped resonator and tapped microstrip Input/output (I/O) lines. An analytic study of the $\mathrm{H}$-shaped resonator and an equivalent $\mathrm{LC}$ model of the proposed $\mathrm{H}$-shaped band-pass filter were introduced. Two cross-slots are etched in the ground plane of the proposed microstrip diplexer in order to enhance its electrical performances and to set the pass bands at low frequencies. The circuit with defected ground structure is able to operate at the GPS L1 and L2 bands. The electrical performances of the diplexer are investigated numerically by using Momentum integrated in ADS from Agilent technologies and verified with another electromagnetic software CST microwave Studio.
\end{abstract}

Index Terms - Band pass filters, Diplexer, Isolation, LC model, Microstrip technology.

\section{INTRODUCTION}

The microwave diplexer represents a key component in modern wireless communication applications. It's generally used to reduce the number of the antennas in Transmit/Receive systems. Known as a three port device that can separate different frequency bands, it allows a single antenna to be shared simultaneously by a transmitter and a receiver operating in different frequency bands. Otherwise it routes the signal from the transmitter to the antenna and from the antenna to the receiver [1].

With the rapid expansion of modern wireless communication systems, the development of planar filters and diplexers with high performances, low losses, high isolation, low cost and small size is currently a research area of a fundamental interest.

Thanks to their low losses and the high power that they can handle, waveguides are mostly used to realize filters and diplexers. However, waveguides have a large size and heavy weight, moreover the fabrication processes of this kind of components is more expensive.

Several approaches have been developed over the last decades to achieve microwave filters and diplexers with high performances such as lumped-elements microwave filters proposed in [2] or the High-Temperature superconducting (HTS) thin films used to achieve microstrip filters [3]. RF filters have also been developed using Surface Acoustic Wave SAW and Bulk Acoustic Wave (BAW) 
resonator technology [4-5]. In fact, these microwave circuits are mostly fabricated based on microstrip transmission lines.

The asymmetric H-shaped filter consists of two taped transmission lines coupled directly with a third bended transmission line used as a coupling patch and two Input/output feed lines. This type of resonators was studied in [6] to improve the attenuation of stop band and to eliminate the unwanted spurious resonant frequencies by using (defected ground structure) DGS. In [7] the H-type resonator is introduced to enhance the narrow bandwidth and the high insertion losses of the serial gap-coupled half-wavelength resonator structure. In addition, in [8] a diplexer with low insertion loss, good isolation between the output ports and a small overall size is proposed based on a two-pole H-type resonator.

In this paper, we present a new topology of a compact microstrip band-pass filter based on modified H-type resonator. The proposed band-pass filter is used to design a new compact microstrip diplexer. The First section of this work begins with an analytic study of the H-shaped resonator. Then, an overview of the equivalent LC model of the proposed band-pass filter with a detailed calculation method is introduced. Secondly, the microstrip diplexer is designed by combining two band-pass filters operating at different frequencies by using a coupled junction. Furthermore, parametric studies were performed to investigate the effect of dimensions variation on the frequency response of the proposed structure. Finally, the defected ground structure technique was utilized to modify the location of resonant frequencies and to enhance the frequency response of the diplexer especially, in terms of return loss and isolation. Thus, a reduction in the form factor can be achieved.

\section{STUDY OF THE H-SHAPED RESONATOR}

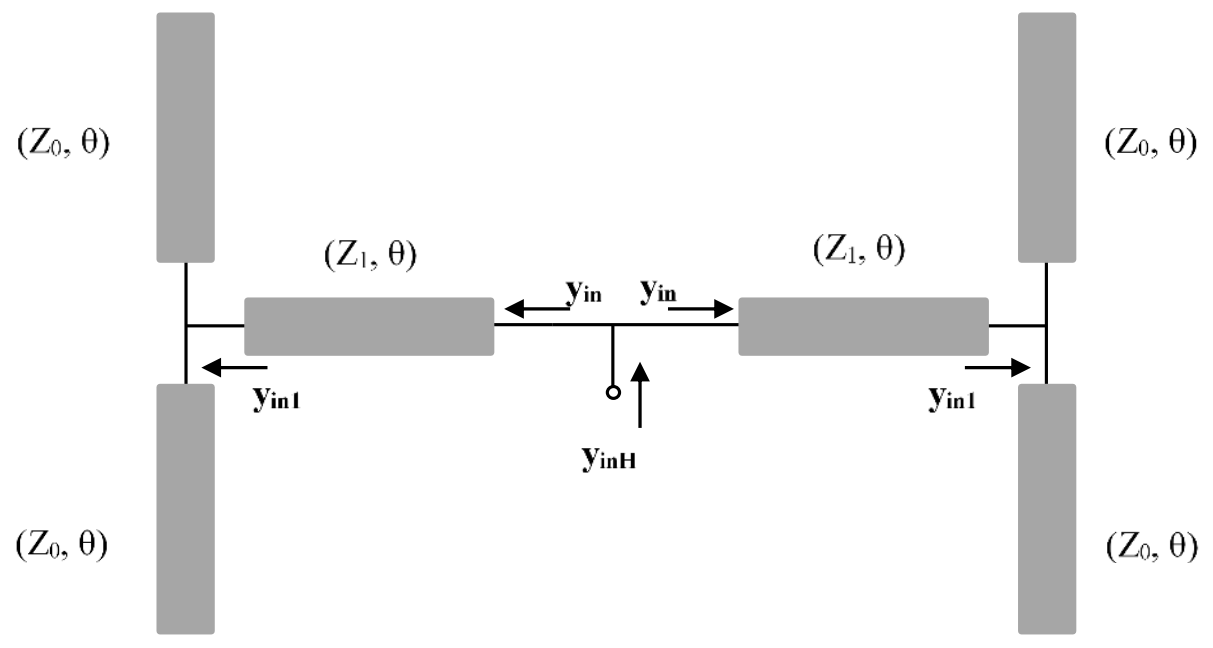

Fig. 1. Microstrip H-shaped resonator. 
To study the H-shaped resonator it's necessary to study the T-shaped resonator [9]. It should be noted that this resonator can be obtained by placing two open stubs having the same characteristic impedance $Z_{0}$ and the electrical length $\theta$ at the end of the input transmission line which has characteristic impedance $Z_{1}$ and an electrical length $\theta$ as shown in Fig. 2.

The expression (1) can be used to calculate the input admittance $\mathrm{Y}_{\mathrm{in} 1}$ :

$$
Y_{i n 1}=\frac{j \operatorname{tg}(\theta)}{Z_{0}}+\frac{j \operatorname{tg}(\theta)}{Z_{0}}
$$

The input admittance of the T-shaped resonator can be analyzed by:

$$
Y_{i n}=\frac{2 j \operatorname{tg} \theta\left(Z_{1}+\frac{Z_{0}}{2}\right)}{Z_{1}\left(Z_{0}-2 Z_{1} \operatorname{tg}^{2} \theta\right)}
$$

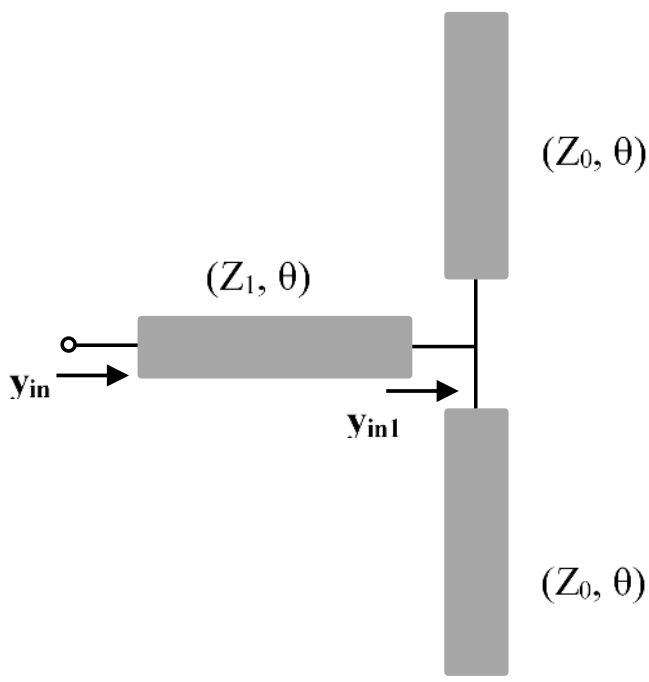

Fig. 2. Microstrip T-shaped resonator.

Consider the H-shaped resonator shown in Fig. 1. As can be seen, this resonator consists of the two T-shaped resonators. The input admittance from the middle of the coupling patch of the resonator can be characterized by the following equation:

$$
\begin{aligned}
& Y_{i n H}=Y_{i n}+Y_{i n} \\
& Y_{i n H}=2 \times \frac{2 j \operatorname{tg} \theta\left(Z_{1}+\frac{Z_{0}}{2}\right)}{Z_{1}\left(Z_{0}-2 Z_{1} \operatorname{tg}^{2} \theta\right)}
\end{aligned}
$$

Thus, the input impedance can be written as follows:

$$
Z_{\text {inH }}=\frac{Z_{1}\left(Z_{0}-2 Z_{1} \operatorname{tg}^{2} \theta\right)}{4 j \operatorname{tg} \theta\left(Z_{1}+\frac{Z_{0}}{2}\right)}
$$

The resonance occurs when input admittance $Y_{\mathrm{inH}}=0$ or the input impedance $\mathrm{Z}_{\mathrm{inH}}=\infty$, so this condition can be written as: 


$$
j \operatorname{tg} \theta\left(Z_{1}+\frac{Z_{0}}{2}\right)=0
$$

Otherwise, we obtain the resonance for a given center frequency when:

$$
\begin{aligned}
& \theta=\pi+n \pi \\
& l=\frac{\lambda}{2}+\frac{k}{2} \lambda \\
& f=\frac{c}{\lambda \sqrt{\varepsilon_{\text {eff }}}}
\end{aligned}
$$

\section{LC MODEL OF THE H-SHAPED BAND-PASS FILTER}

The design procedure of the proposed microstrip diplexer begins by the design of the band-pass filter based on the primary $\mathrm{H}$-resonator. The structure of the $\mathrm{H}$ resonator is modified to obtain the proposed band-pass filter shown in the Fig. 3. In order to examine and to study this new topology, the microstrip structure is then converted to the LC model shown the Fig. 4.

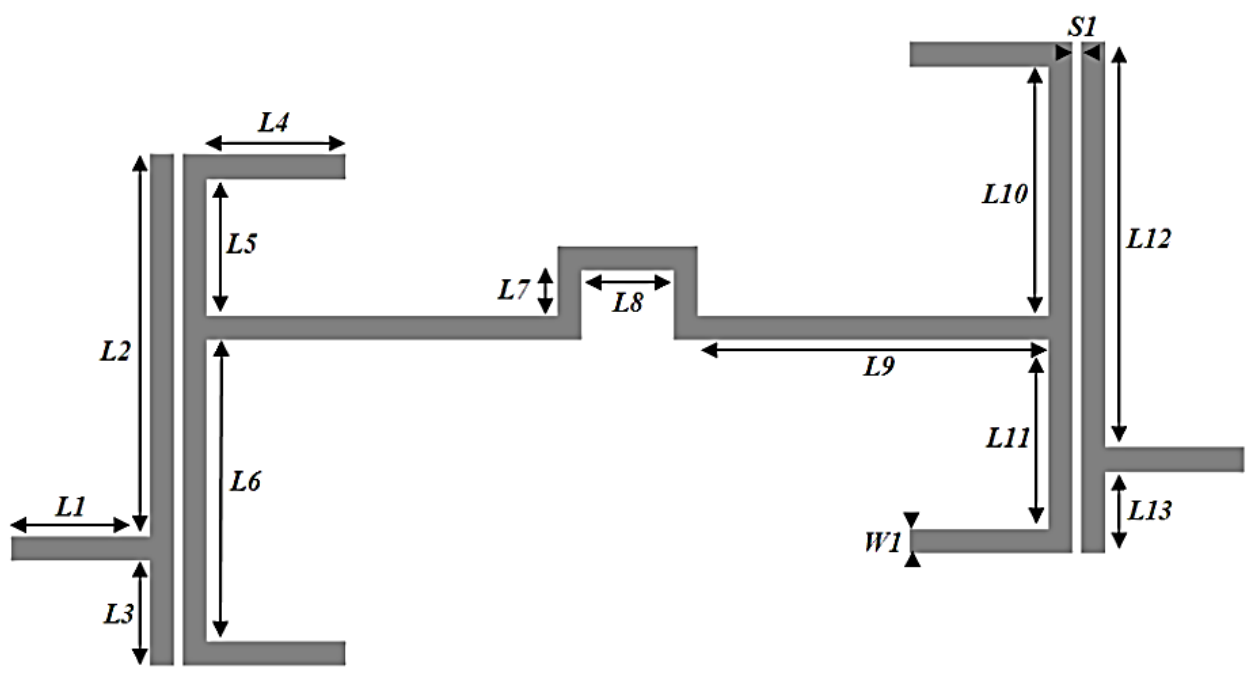

Fig. 3. The topology of the proposed microstrip band pass filter.

The dimensions of the proposed band-pass filter using modified $\mathrm{H}$-shaped resonator are:

$\mathrm{W} 1=0.5, \mathrm{~S} 1=0.2, \mathrm{~L} 1=3, \mathrm{~L} 2=8.24, \mathrm{~L} 3=2.26, \mathrm{~L} 4=3, \mathrm{~L} 5=2.97, \mathrm{~L} 6=6.53, \mathrm{~L} 7=1, \mathrm{~L} 8=2, \mathrm{~L} 9=7.6$, $\mathrm{L} 10=5.39, \mathrm{~L} 11=4.11, \mathrm{~L} 12=8.74, \mathrm{~L} 13=1.76$, all in $(\mathrm{mm})$.

The LC model of the modified $\mathrm{H}$-shaped resonator was obtained by converting every microstrip line to its equivalent LC component. This work is performed by using the basic LC model of the Tshaped resonator discussed in [10] and the LC model of the band-pass filter using the open-stub presented in [11]. The values of each LC component were calculated by using the expressions (9) and (10).

$$
l=C Z_{c} v_{p}
$$




$$
l=\frac{L v_{p}}{Z_{c}}
$$

For a constant line width, the parameters $l, \mathrm{C}$ and $\mathrm{L}$ represent the length, the capacitance and the inductance of a microstrip line. While $\mathrm{Z}_{\mathrm{c}}$ is the characteristic impedance and $v_{p}$ represents the phase velocity.

Calculating the $\mathrm{C}$ and $\mathrm{L}$ expressions passes through the calculation of inevitable other equations. The equations (11-17) were used for this reason.

Once the effective dielectric constant $\varepsilon_{\mathrm{re}}$ is determined, the phase velocity is given by:

$$
v_{p}=\frac{c}{\sqrt{\varepsilon_{r e}}}
$$

c represents the velocity of light in free space.

The effective dielectric constant $\varepsilon_{\mathrm{re}}$ and the characteristic impedance $\mathrm{Z}_{\mathrm{c}}$ can be determined by:

For $W / h \leq 1$

$$
\begin{gathered}
\varepsilon_{r e}=\frac{\varepsilon_{r}+1}{2}+\frac{\varepsilon_{r}-1}{2}\left\{\left(1+12 \frac{h}{W}\right)^{-0.5}+0.04\left(1-\frac{W}{h}\right)^{2}\right\} \\
Z_{c}=\frac{\eta}{2 \pi \sqrt{\varepsilon_{r e}}} \ln \left[8 \frac{h}{W}+0.25 \frac{W}{h}\right]
\end{gathered}
$$

For $W / h \geq 1$

$$
\begin{gathered}
\varepsilon_{r e}=\frac{\varepsilon_{r}+1}{2}+\frac{\varepsilon_{r}-1}{2}\left(1+12 \frac{h}{W}\right)^{-0.5} \\
Z_{c}=\frac{\eta}{\sqrt{\varepsilon_{r e}}}\left[\frac{h}{W}+1.393+0.677 \ln \left\{\frac{W}{h}+1.444\right\}\right]^{-1}
\end{gathered}
$$

Where $w$ is the width of the microstrip line, $h$ and $\varepsilon_{\mathrm{r}}$ represent the thickness and the permittivity of the substrate, $\varepsilon_{\mathrm{re}}$ is the effective permittivity, the parameter $\eta=120 \pi \Omega$ is the wave impedance in free space.

For the right angle bends of the coupled patch, they can be modeled by an equivalent T- network as described in [12]. An approximate form to evaluate the value of the capacitance can be given by the following expressions.

$$
\begin{gathered}
\frac{C}{W}(p F / m)=\frac{\left(14 \varepsilon_{r}+12.5\right) W / h-\left(1.83 \varepsilon_{r}-2.25\right)}{\sqrt{W / h}}+\frac{0.02 \varepsilon_{r}}{W / h} \text { for } W / h<1 \\
\frac{C}{W}(p F / m)=\left(9.5 \varepsilon_{r}+1.25\right) W / h+5.2 \varepsilon_{r}+7 \text { for } W / h>1
\end{gathered}
$$




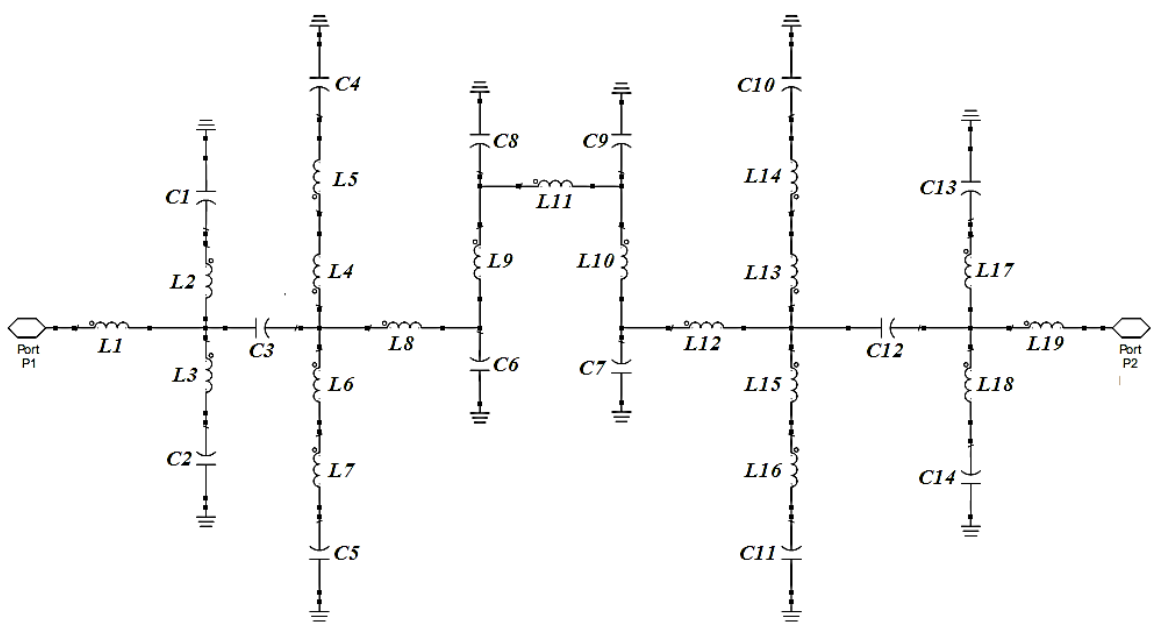

Fig. 4. The LC model of the proposed band pass filter.

TABLE I. THE VALUES OF THE LC MODEL COMPONENTS.

\begin{tabular}{ccccc}
\hline $\mathrm{L} 1(\mathrm{nH})$ & $\mathrm{L} 2(\mathrm{nH})$ & $\mathrm{L} 3(\mathrm{nH})$ & $\mathrm{L} 4(\mathrm{nH})$ & $\mathrm{L} 5(\mathrm{nH})$ \\
1.95 & 5.35 & 1.46 & 1.9 & 1.9 \\
$\mathrm{~L} 6(\mathrm{nH})$ & $\mathrm{L} 7(\mathrm{nH})$ & $\mathrm{L} 8(\mathrm{nH})$ & $\mathrm{L} 9(\mathrm{nH})$ & $\mathrm{L} 10(\mathrm{nH})$ \\
4 & 1.9 & 4.9 & 0.6 & 0.6 \\
$\mathrm{~L} 11(\mathrm{nH})$ & $\mathrm{L} 12(\mathrm{nH})$ & $\mathrm{L} 13(\mathrm{nH})$ & $\mathrm{L} 14(\mathrm{nH})$ & $\mathrm{L} 15(\mathrm{nH})$ \\
1.2 & 4.9 & 3.4 & 1.9 & 2.6 \\
$\mathrm{~L} 16(\mathrm{nH})$ & $\mathrm{L} 17(\mathrm{nH})$ & $\mathrm{L} 18(\mathrm{nH})$ & $\mathrm{L} 19(\mathrm{nH})$ & \\
1.9 & 5.6 & 1.1 & 1.95 & \\
$\mathrm{C} 1(\mathrm{pF})$ & $\mathrm{C} 2(\mathrm{pF})$ & $\mathrm{C} 3(\mathrm{pF})$ & $\mathrm{C} 4(\mathrm{pF})$ & $\mathrm{C} 5(\mathrm{pF})$ \\
0.42 & 0.115 & 0.4 & 0.3 & 0.4 \\
$\mathrm{C} 6(\mathrm{pF})$ & $\mathrm{C} 7(\mathrm{pF})$ & $\mathrm{C} 8(\mathrm{pF})$ & $\mathrm{C} 9(\mathrm{pF})$ & $\mathrm{C} 10(\mathrm{pF})$ \\
0.015 & 0.015 & 0.015 & 0.015 & 0.4 \\
$\mathrm{C} 11(\mathrm{pF})$ & $\mathrm{C} 12(\mathrm{pF})$ & $\mathrm{C} 13(\mathrm{pF})$ & $\mathrm{C} 14(\mathrm{pF})$ & \\
0.3 & 0.4 & 0.44 & 0.089 & \\
\hline
\end{tabular}

Depending on the calculation method mentioned above, the values of each component in the equivalent LC model are calculated and listed in Table I. For a line width equal to $0.5 \mathrm{~mm}$ the calculated values of the effective dielectric constant and the characteristic impedance are $\left(\varepsilon_{\mathrm{re}}=3.004\right.$, $\mathrm{Z}_{\mathrm{c}}=112.36 \Omega$ ). The simulated results of the microstrip filter and its equivalent LC model are shown in Fig. 5. It can be clearly seen that there is a good agreement between the two frequency responses. This agreement confirms the method utilized in the extracted LC model and the values of its elements.

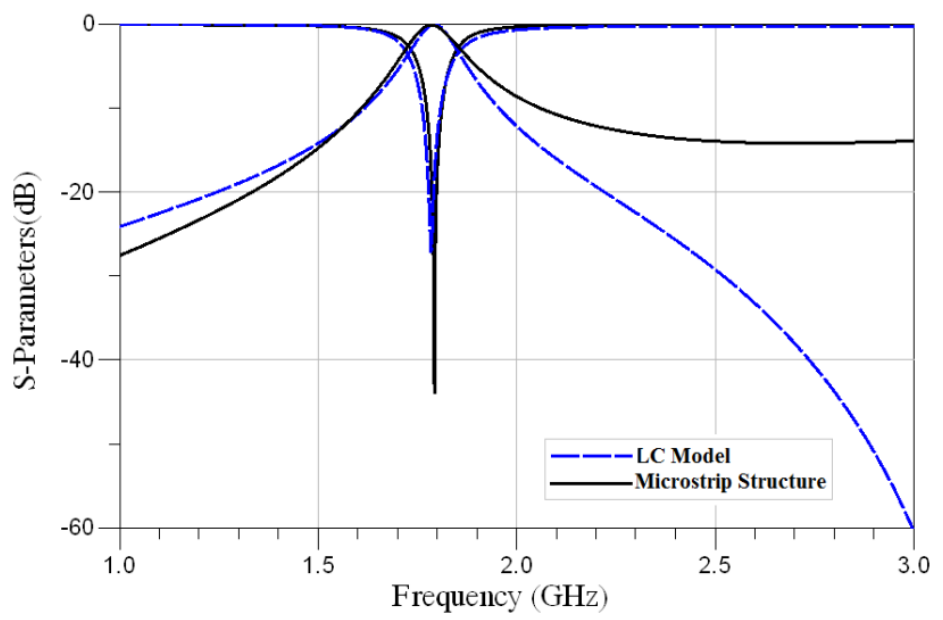

Fig. 5. Simulated results of the LC model and the Microstrip band-pass filter. 


\section{DESIGN OF MICROSTRIP DIPLEXER}

In general, the design approach of a diplexer begins by the design of the two band-pass filters [1]. In order to improve the isolation between the two pass bands of the circuit, it is important to choose a topology with a high selectivity level [13]. Among all the topologies used, filters with transmission zeros represents a good possibility to obtain the desired frequency response. In fact, by using such topologies with pseudo-elliptic frequency response, the stop band can be controlled by positioning appropriately the transmission zeros $[14,15]$. Therefore, it is possible to realize a band-pass filter with high-level rejection, a limited order, reduced size, and low losses.

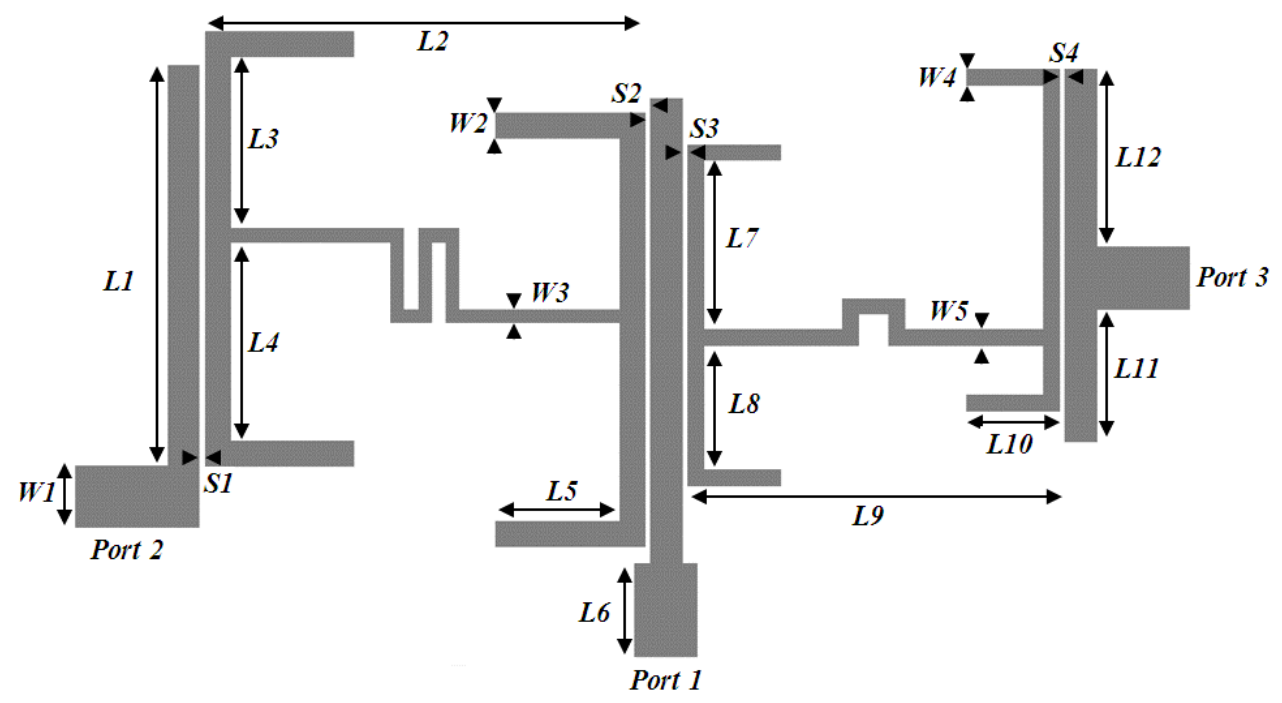

Fig. 6. Schematic of the microstrip diplexer for GPS and ISM applications.

The structure of the proposed diplexer is shown in Fig. 6, whose design parameters were determined as follows:

$\mathrm{W} 1=2, \mathrm{~W} 2=4, \mathrm{~W} 3=0.4, \mathrm{~W} 4=0.5, \mathrm{~W} 5=0.5, \mathrm{~L} 1=14, \mathrm{~L} 2=14.4, \mathrm{~L} 3=5.5, \mathrm{~L} 4=6.44, \mathrm{~L} 5=4.5, \mathrm{~L} 6=3$, $\mathrm{L} 7=5.47, \mathrm{~L} 8=4, \mathrm{~L} 9=13.22, \mathrm{~L} 10=2.5, \mathrm{~L} 11=4.26, \mathrm{~L} 12=5.74, \mathrm{~S} 1=0.2, \mathrm{~S} 2=0.2, \mathrm{~S} 3=0.2, \mathrm{~S} 4=0.2$, all in (mm).

The transmit filter (Tx) is the circuit which operates in the $1.575 \mathrm{GHz}$ band while the filter centered at $2.4 \mathrm{GHz}$ is denoted the receive filter $(\mathrm{Rx})$. As depicted in Fig. 6, the proposed diplexer is formed by connecting two-band pass filters designed based on the modified $\mathrm{H}$-shaped resonators and tapped Input/output (I/O) feed lines. The end-open feed lines dedicated to the input and the output of diplexer are placed in close proximity to each resonator; the antenna port is connected directly to an open-end feed line and coupled to the two resonators. The junction between the $\mathrm{Tx}$ and $\mathrm{Rx}$ filters can be realized by different coupling structures, the T-junction or the $\mathrm{Y}$-junction remain the most used ones, however diplexers with such configurations occupy a considerable footprint [16]. The coupled-junction is proposed to achieve high performances, not only to reduce the diplexer size but also to obtain better insertion loss and rejection performances [17]. 
The proposed band-pass filter is a modified configuration of the second order half-wavelength resonators proposed in [7]. The resonance frequency of the filters that utilize such resonators can be adjusted by changing the total length of the resonator. It can be noticed that the resonant frequency can be obtained by the expression (8).

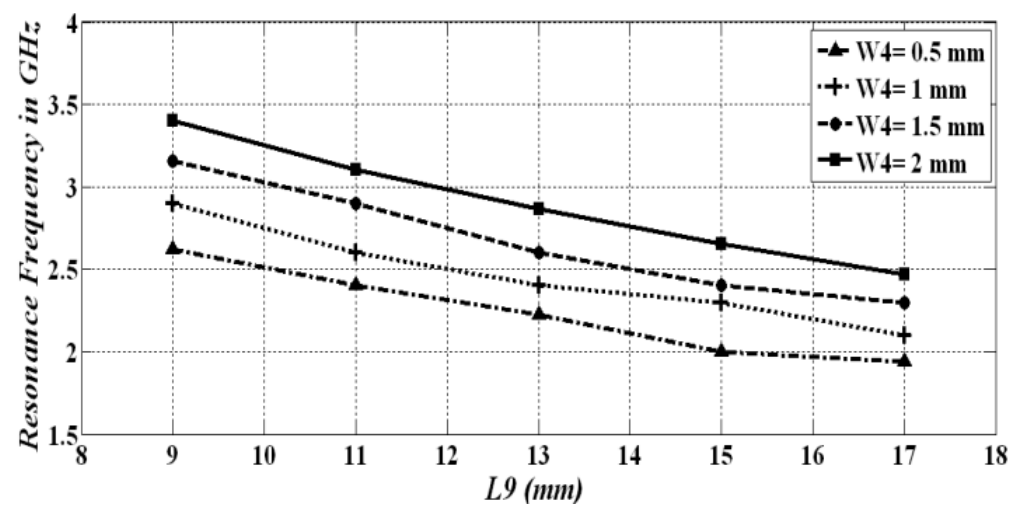

(a)

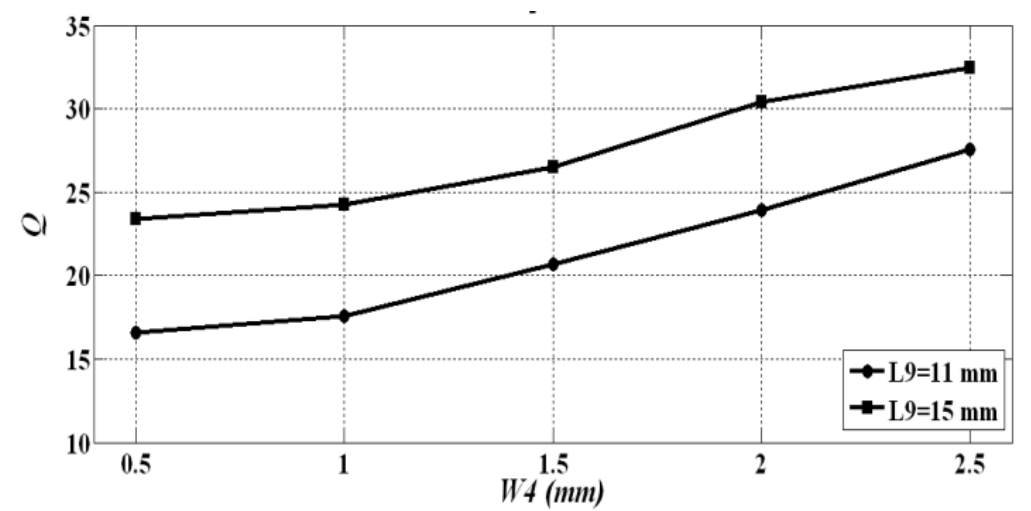

(b)

Fig. 7. (a) Resonance frequency versus the length of the coupling patch $\mathrm{L}_{9}$ for different values of width $\mathrm{W}_{4}$ (b) External coupling coefficient $\mathrm{Q}$ versus the width of the coupling patch $\mathrm{W}_{4}$.

Several parametrical studies are achieved to analyze the behavior of the modified H-shaped resonator under different values of the width and the length of the coupling patch. Fig. 7 shows the evolution of the resonant frequency and the quality factor $\mathrm{Q}$ under different values of the width and the length of the coupling patch.

The full-wave electromagnetic simulator ADS is used to extract the external quality factor Q. The external quality factor Q can be calculated by the expression (18) [18].

$$
Q_{e}=\frac{2 Q_{0} Q_{L}}{\left(Q_{0}-Q_{L}\right)}
$$

Where $\mathrm{Q}_{0}$ is the unloaded quality factor while $\mathrm{Q}_{\mathrm{L}}$ is the loaded quality factor obtained by the following formulas:

$$
Q_{L}=\frac{1}{\frac{2}{Q_{e}}+\frac{1}{Q_{0}}}=\frac{f_{0}}{(\Delta f)_{3 d B}}
$$




$$
Q_{0}=\frac{Q_{L}}{\left(1-10^{-L / 20}\right)}
$$

With $f_{0}$ is the resonant frequency, $(\Delta \mathrm{f})_{3 \mathrm{~dB}}$ is the $-3 \mathrm{~dB}$ bandwidth of the pass band, $\mathrm{L}$ is the insertion loss in decibel.

Fig. 7 depicts the relation between the external quality factor $Q$ of the Rx filter and the width of the coupling patch $\mathrm{W}_{4}$. It is known that the external quality factor depends on the resonant frequency and bandwidth. Therefore, for a fixed value of $\mathrm{L}_{9}$ and $\mathrm{W}_{4}$, the resonant frequency, the external quality factor, and the bandwidth can be easily determined. As it shown in the Fig. 7.b we can clearly observe that the quality factor $\mathrm{Q}$ increases when we increase the width from $0.5 \mathrm{~mm}$ to $2.5 \mathrm{~mm}$. Moreover, the length of the coupling patch can affect the external quality factor $Q$ when the length L9 varies from 11 $\mathrm{mm}$ to $15 \mathrm{~mm}$ for different values of $\mathrm{W}_{4}$. From the Fig. 7.a the resonance frequency can reach 3.4 $\mathrm{GHz}$ for a width of $2 \mathrm{~mm}$ and a length of $9 \mathrm{~mm}$, and $1.9 \mathrm{GHz}$ for a width of $0.5 \mathrm{~mm}$ and a length of 17 $\mathrm{mm}$.

Contrary to the results obtained in [6], keeping a constant width and increasing the length of the coupling patch from $9 \mathrm{~mm}$ to $17 \mathrm{~mm}$ decrease the resonant frequency. The same behavior is observed when we keep the length constant and we decrease the width from $2 \mathrm{~mm}$ to $0.5 \mathrm{~mm}$.

\section{RESULTS AND DISCUSSION}

After studying the characteristics of the modified $\mathrm{H}$-shaped resonator, the full-wave electromagnetic simulator ADS [19] is used to characterize the frequency response of the diplexer. The substrate used in the design of the proposed diplexer is the FR4 with a thickness of $1.6 \mathrm{~mm}$, a relative electric constant of 4.4, a loss tangent of 0.025 and a conductor thickness of $35 \mathrm{um}$. The size of the proposed diplexer is extremely small, with an area equal to $(37.5 \mathrm{~mm} \times 21 \mathrm{~mm})$.

The simulation results of the proposed diplexer are shown in Fig. 8. Low insertion loss, good rejection and high isolation can be clearly observed.

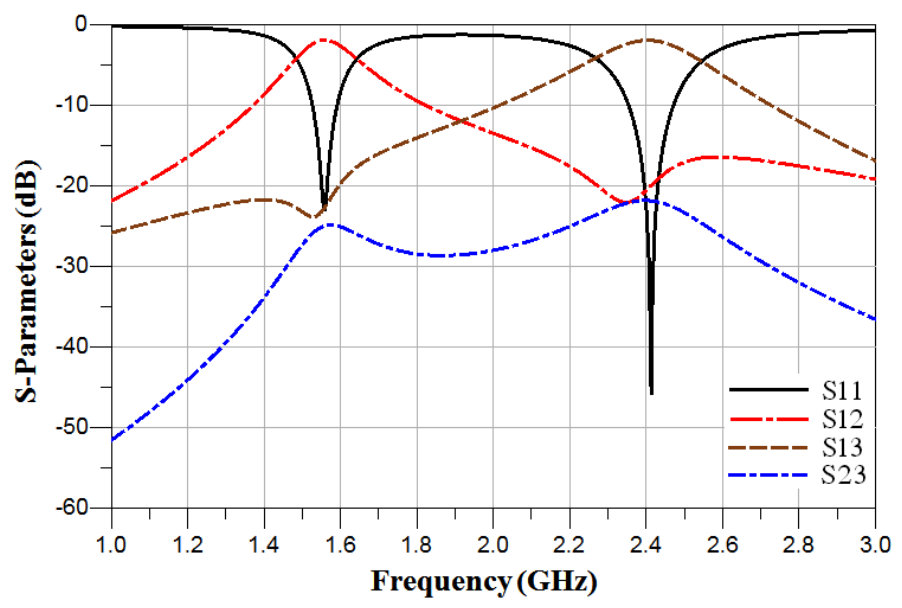

(a) 


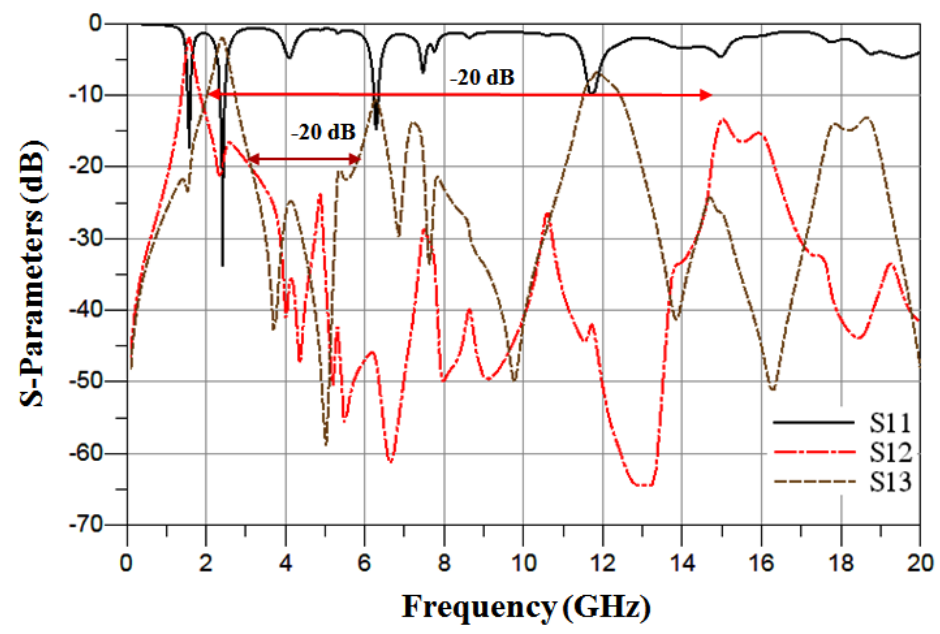

(b)

Fig. 8. (a) Simulation results of the proposed diplexer by using ADS. (b) Simulation results of the fundamental and the first spurious frequencies of the designed diplexer.

As shown in Fig. 8.a, the simulated bandwidth is about $6.17 \%$ and $6.9 \%$ for the low and the high band respectively. The insertion loss is about $2 \mathrm{~dB}$ for the $\mathrm{Rx}$ filter and $1.9 \mathrm{~dB}$ for the Tx filter. The return loss is about $23 \mathrm{~dB}$ and $30 \mathrm{~dB}$ for the upper and lower filter respectively while the isolation between the two channels is better than $21.8 \mathrm{~dB}$ at the center frequency of $2.4 \mathrm{GHz}$. In addition, several transmission zeros near the pass bands are located at $1.5 \mathrm{GHz}, 2.3 \mathrm{GHz}, 3.7 \mathrm{GHz}$ and $3.9 \mathrm{GHz}$ with attenuation of $24 \mathrm{~dB}, 22 \mathrm{~dB}, 43 \mathrm{~dB}$ and $44 \mathrm{~dB}$ respectively. These transmission zeros are expected to improve band selectivity and the isolation of the proposed diplexer.

In this work, a simple method has been used to determine the resonant frequency of the H-shaped resonator. Furthermore, the spurious frequencies can be controlled by carefully adjusting the dimensions of each resonator. It should be noted that, better isolation can be obtained with a high order filter. However, this design approach shows that with reduced order resonators, compact bandpass filters with wide stop band and good performances can be easily designed. As shown in Fig. 8.b the stop band of the receiving channel is extended up to $5.78 \mathrm{GHz}$ with an insertion loss larger than 20 $\mathrm{dB}$. In addition, the band-pass filter operating at $1.575 \mathrm{GHz}$ has an attenuation level better than $20 \mathrm{~dB}$ up to $14.24 \mathrm{GHz}$. Thereby; a wide stop band is obtained for Tx filter.

Then, CST-MWS [20] is also used to design and to evaluate the frequency response of the circuit in order to verify its electrical performances. Further, the CST-MWS is used to study the group delay time and the electrical filed distribution of the diplexer.

Fig. 9.a depicts the simulated results of the proposed diplexer by using the CST-MWS. As seen the insertion losses at the lower and the higher bands are less than $2 \mathrm{~dB}$. While the return losses are approximately $16.8 \mathrm{~dB}$ and $21 \mathrm{~dB}$ for the $\mathrm{Tx}$ and the $\mathrm{Rx}$ filters respectively. The isolation between the two channels is greater than $21.5 \mathrm{~dB}$. In addition, the simulated $3 \mathrm{~dB}$ FBWs are about $8.35 \%$ at $1.58 \mathrm{GHz}$ and $7.6 \%$ at $2.38 \mathrm{GHz}$ respectively.

Moreover, the simulated group delay time for the download and the upload band depicted in Fig. 9.b is defined from 1.2 to $1.6 \mathrm{~ns}$ and from 0.8 to $1.3 \mathrm{~ns}$ respectively. We can observe that, the group 
delay time is extremely small and flat.

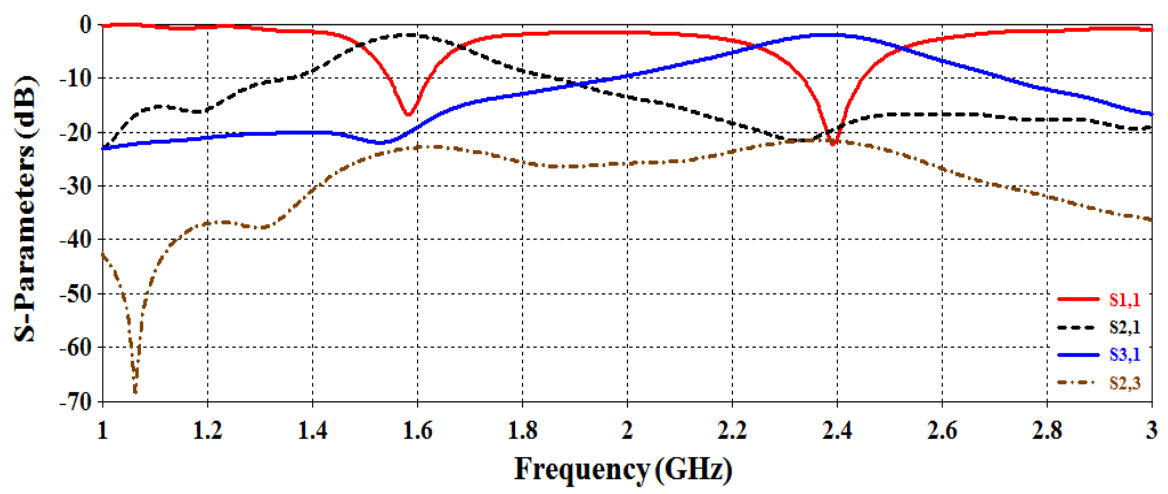

(a)

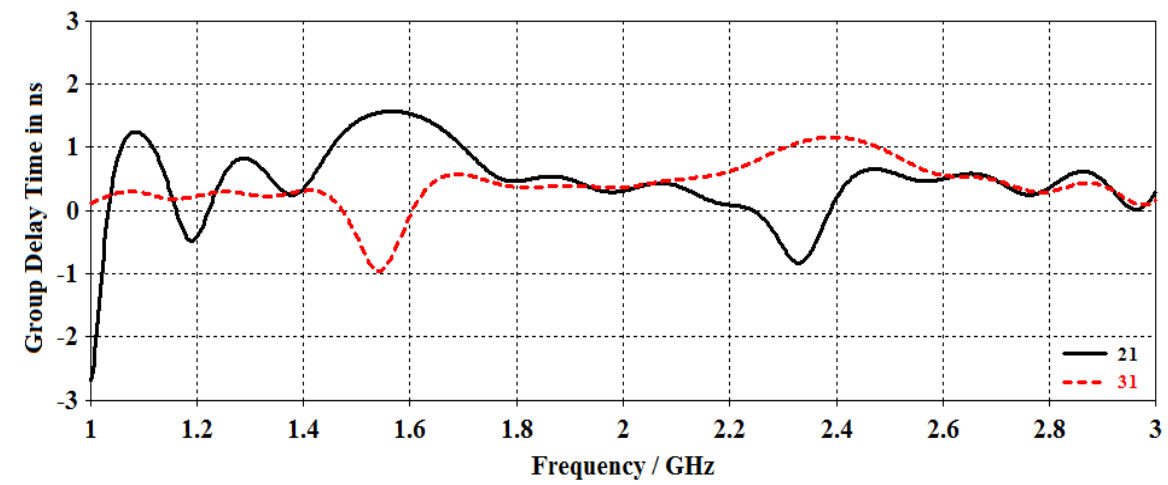

(b)

Fig. 9. (a) S-Parameters results and (b) Simulated group delay time of the proposed diplexer by using CSTMWS.

Table II presents a comparison between the simulated results with CST-MWS and ADS. As can be clearly seen, simulated results with ADS agree well with the simulation results obtained with CSTMWS.

TABLE II. COMPARISON BETWEEN THE SIMULATIONS RESULTS OBTAINED WITH ADS AND CST-MWS.

\begin{tabular}{lcccc}
\hline Parameter & \multicolumn{2}{c}{ Simulation results (ADS) } & \multicolumn{2}{c}{ Simulation results (CST) } \\
& TX & RX & TX & RX \\
\hline Frequency GHz & 1.557 & 2.4 & 1.580 & 2.38 \\
Bandwidth & $96 \mathrm{MHz}$ & $166 \mathrm{MHz}$ & $132 \mathrm{MHz}$ & $182 \mathrm{MHz}$ \\
Insertion loss $[\mathrm{dB}]$ & 1.98 & 2 & 2 & 1.9 \\
Return loss $[\mathrm{dB}]$ & 23 & 30 & 17 & 21 \\
\hline
\end{tabular}

Fig. 10 shows the electrical-field distributions of the $\mathrm{H}$-shaped diplexer at $1.575 \mathrm{GHz}$ and $2.4 \mathrm{GHz}$. We can observe that the concentration of the current in the margin of the $\mathrm{H}$-shaped resonator is larger compared with the current density in the coupling patch. Fig. 10.a presents the electrical-field distribution of the proposed diplexer at $1.575 \mathrm{GHz}$; we can observe that the current is concentrated at the H-shaped resonator of the lower pass band filter. In counterpart, Fig. 10.b plots the electrical-field distribution at $2.4 \mathrm{GHz}$. It can be seen that the concentration of the current at the higher pass band filter is very large. 


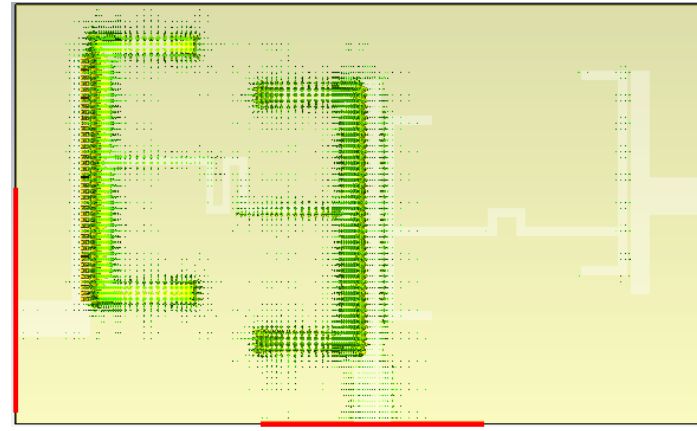

(a)

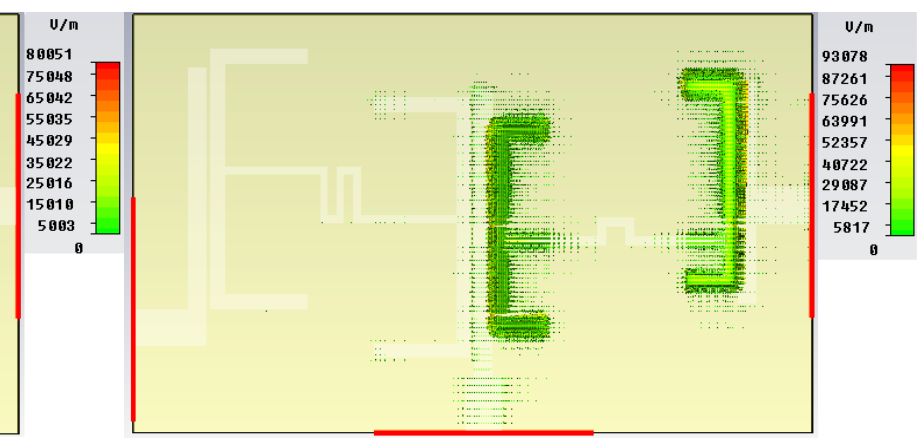

(b)

Fig. 10. Electrical-field distribution at (a) $1.575 \mathrm{GHz}$ and (b) $2.4 \mathrm{GHz}$.

\section{MICROSTRIP DIPLEXER WITH DEFECTED GROUND STRUCTURE}

Defected ground structure or the DGS technology has been proposed for the first time in [21]. This technique was widely used to design circuits dedicated to filtering applications [22,23,24]. In fact, this structure is achieved by engraving slots in the ground plane of the circuit in order to disturb the current distribution, thus the characteristics of the transmission lines can be modified. This technique is used to increase the stopband and to set the resonant frequencies of each microstrip resonator at low frequencies which is beneficial for the miniaturization of the proposed diplexer. In this work, the DGS technique is introduced to enhance the electrical performances of the proposed diplexer.

Fig. 11 shows the backside of the substrate with the slots introduced to control the resonant frequencies and to improve the electrical performances of the diplexer. The circuit is designed and simulated by using the electromagnetic solver CST-MWS.

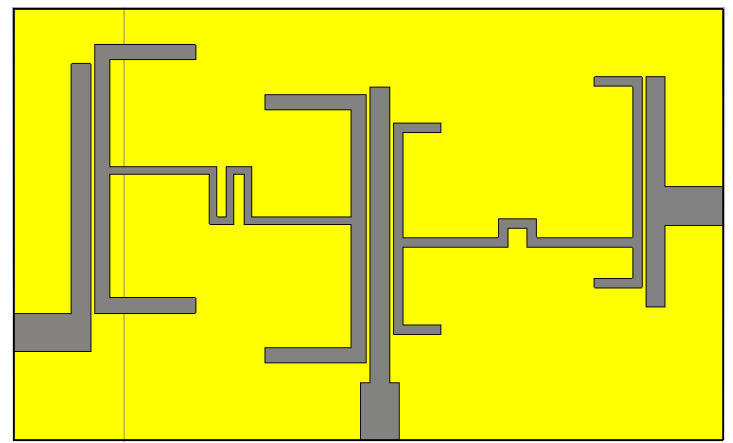

(a)

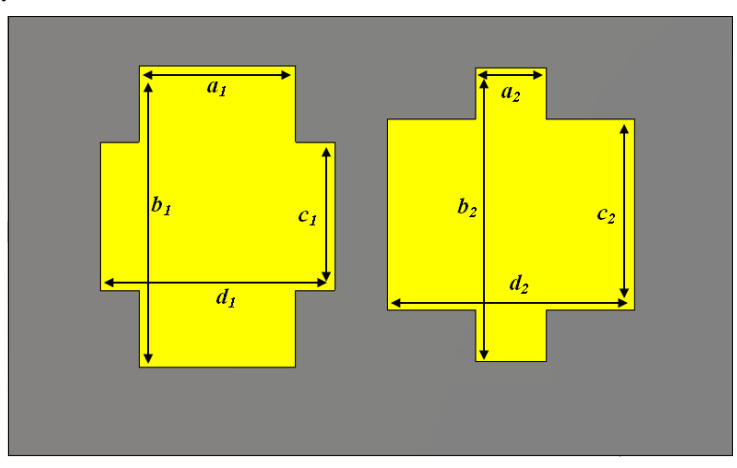

(b)

Fig. 11. (a) The proposed microstrip diplexer (b) Layout of the defected ground slots.

In fact, the insertion loss, return loss, isolation and the relative size of the two BPFs are crucial parameters in the diplexer design. Thus, each one of these parameters must be taken into account to get a better frequency response. As it can be seen in the Fig. 10, the concentration of the current in the margin of the $\mathrm{H}$-shaped resonator is larger. In this case, two cross slots have been etched directly under the modified $\mathrm{H}$-shaped resonators.

Several simulations have been achieved in order to get the desired frequency response. It can be noticed that, to control the resonant frequencies of the proposed circuit it is necessary to modify the dimensions of each slot $[25,26]$. The final geometrical parameters of the two cross slots are:

$\mathrm{a} 1=8, \mathrm{~b} 1=15.42, \mathrm{c} 1=7.58, \mathrm{~d} 1=12, \mathrm{a} 2=3.6, \mathrm{~b} 2=15.01, \mathrm{c} 2=9.79, \mathrm{~d} 2=12.6$. 
The simulation results of the proposed microstrip diplexer with defected ground structure are presented in Fig. 12.

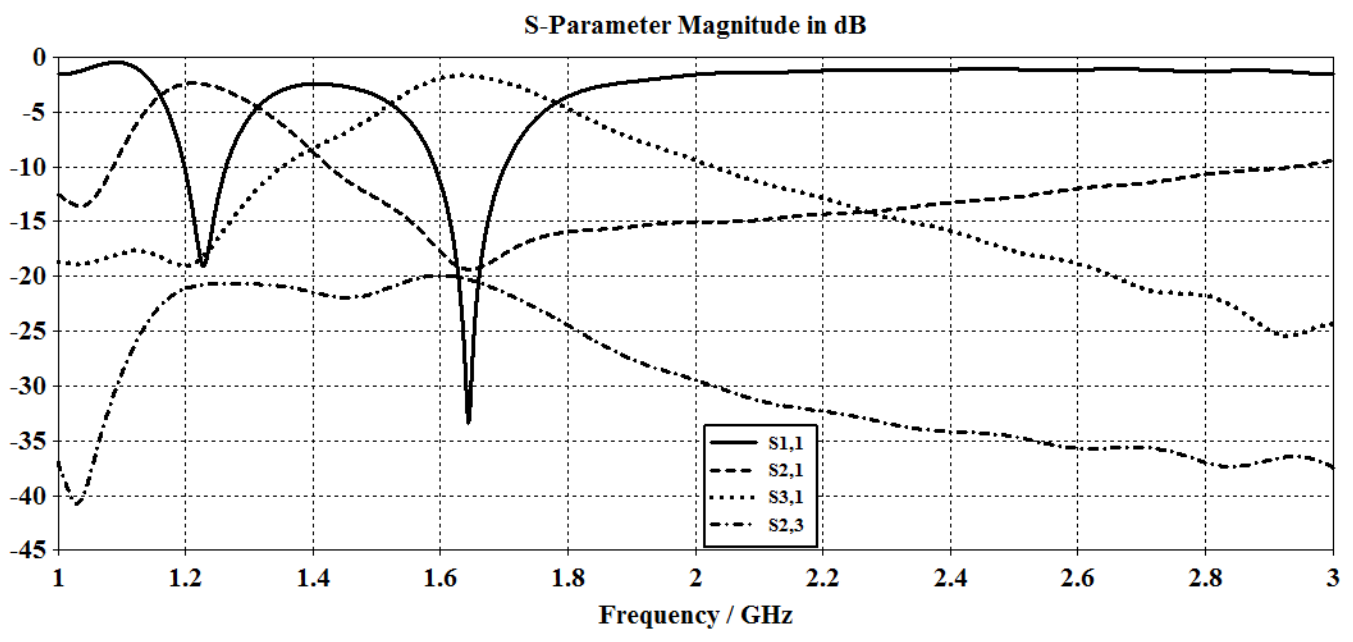

Fig.12. The simulation results of the proposed microstrip diplexer with defected ground structure by using CSTMWS.

From the Fig. 12, it can be seen that after the incorporation of the slots in the ground plane of the microstrip diplexer, good simulation results are obtained. The insertion loss remains lower than 2.4 $\mathrm{dB}$ and $1.7 \mathrm{~dB}$ for the download band and the upload band respectively. The return loss is around 19 $\mathrm{dB}$ for the transmission channel at $1.214 \mathrm{GHz}$ and $25 \mathrm{~dB}$ for the receiving one at $1.636 \mathrm{GHz}$. Moreover, the simulated isolation between the two channels is better than $19.9 \mathrm{db}$. Table III gives a comparison between the simulation results obtained with the CST-MWS solver before and after the integration of the cross slots in the ground plane of the circuit. From the table below we can deduce that without changing the first circuit it is possible to create another diplexer operable in other pass bands. This microstrip diplexer using defected ground structure is suitable to operate for the GPS applications at GPS L1 1575.42 MHz and GPS L2 at 1227.6 MHz.

TABLE III. COMPARISON BETWEEN THE SIMULATIONS RESULTS OF THE PROPOSED DIPLEXER BEFORE AND AFTER INCORPORATING THE CROSS SLOTS.

\begin{tabular}{|c|c|c|c|c|}
\hline \multirow[t]{2}{*}{ Parameter } & \multicolumn{2}{|c|}{ Simulation results (Without DGS) } & \multicolumn{2}{|c|}{ Simulation results (With DGS) } \\
\hline & TX & $\mathbf{R X}$ & TX & $\mathbf{R X}$ \\
\hline Frequency GHz & 1.580 & 2.38 & 1.214 & 1.636 \\
\hline Bandwidth & $132 \mathrm{MHz}$ & $182 \mathrm{MHz}$ & $88 \mathrm{MHz}$ & $180 \mathrm{MHz}$ \\
\hline Insertion loss $[\mathrm{dB}]$ & 2 & 1.9 & 2.4 & 1.7 \\
\hline Return loss [dB] & 17 & 21 & 19 & 25 \\
\hline Isolation $[\mathrm{dB}]$ & \multicolumn{2}{|c|}{21.5} & \multicolumn{2}{|c|}{19.9} \\
\hline
\end{tabular}




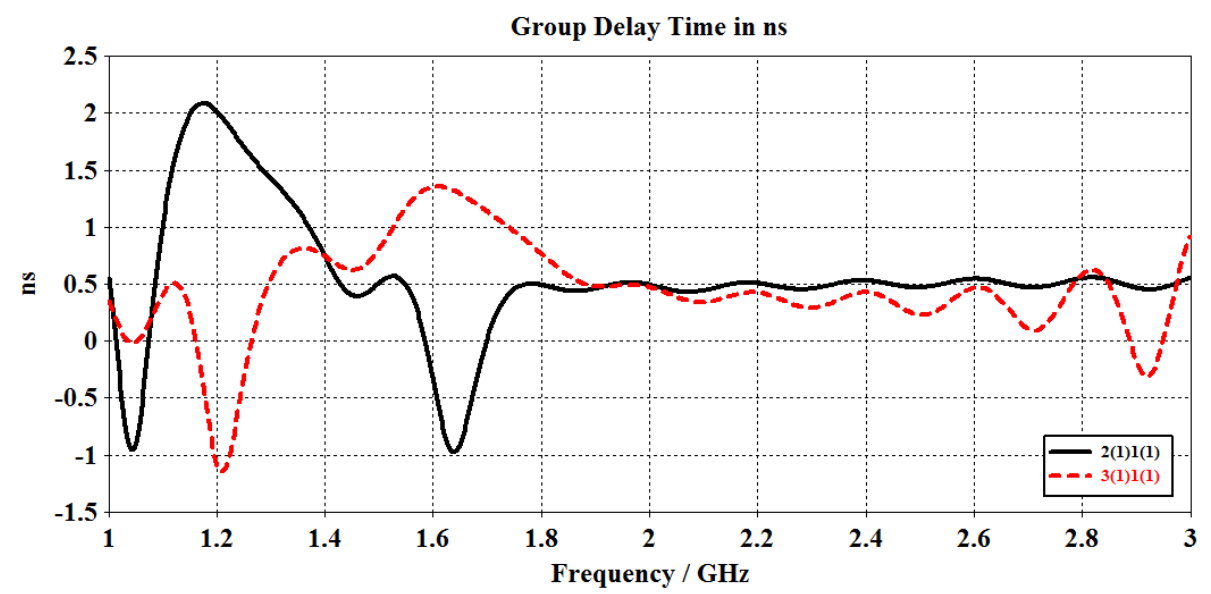

Fig. 13. Simulated group delay time of the proposed diplexer with DGS by using CST-MWS.

The Fig. 13 presents the group delay time of the proposed circuit with DGS. As can be seen, the simulated group delay time is defined from 1.6 to $2.1 \mathrm{~ns}$ for the pass band located at $1.214 \mathrm{GHz}$ and from $1.05 \mathrm{~ns}$ to $1.36 \mathrm{~ns}$ for the pass band located at $1.636 \mathrm{GHz}$.

Compared to the simulation results of the first circuit without DGS, it can be concluded that the introduction of the DGS technique increases the group delay time of the proposed diplexer. This means that the signal takes more time to be routed from a port to another.

TABLE IV. COMPARISON BETWEEN THE PROPOSED DIPLEXER AND OTHER WORKS PROPOSED IN LITERATURE.

\begin{tabular}{|c|c|c|c|c|c|c|c|}
\hline & \multirow{2}{*}{$\begin{array}{c}\begin{array}{c}\text { Center } \\
\text { frequency } f_{0} \\
\text { in GHz }\end{array} \\
\mathbf{T x} / \mathbf{R x}\end{array}$} & \multicolumn{2}{|c|}{$\left|\mathbf{S}_{12}\right| /\left|\mathbf{S}_{11}\right|(\mathbf{d B})$} & \multicolumn{2}{|c|}{-3 dB FBW (\%) } & \multirow{2}{*}{$\begin{array}{l}\text { Isolation in } \\
\text { (dB) }\end{array}$} & \multirow{2}{*}{$\begin{array}{c}\text { Circuit size } \\
\left(\mathrm{mm}^{2}\right)\end{array}$} \\
\hline & & $\mathbf{T x}$ & $\mathbf{R x}$ & $\mathbf{T x}$ & $\mathbf{R x}$ & & \\
\hline Ref [18] & $1.5 / 2$ & $2.7 / 20$ & $2.8 / 20$ & 3.4 & 3.4 & 40 & $33.9 \times 54.4$ \\
\hline Ref [27] & $2.4 / 3.2$ & $1.7 / 30$ & $1.38 / 30$ & 3.5 & 4.7 & 23 & $16 \times 47$ \\
\hline $\operatorname{Ref}[28]$ & $1.8 / 2.4$ & $2.17 / 25$ & $1.7 / 35$ & 5.5 & 9.7 & 22.4 & $40 \times 17$ \\
\hline $\operatorname{Ref}[29]$ & $1.95 / 2.14$ & $1.22 / 15$ & $1.12 / 15$ & 3.1 & 2.8 & 30 & $40 \times 70$ \\
\hline $\begin{array}{l}\text { Proposed } \\
\text { circuit } \\
\text { without } \\
\text { DGS }\end{array}$ & $1.58 / 2.38$ & $2 / 17$ & $1.9 / 21$ & 8.35 & 7.6 & 21.5 & $37 \times 21$ \\
\hline $\begin{array}{l}\text { Proposed } \\
\text { circuit with } \\
\text { DGS }\end{array}$ & $1.2 / 1.6$ & $2.4 / 19$ & $1.7 / 25$ & 7.3 & 11.25 & 20 & $37 \times 21$ \\
\hline
\end{tabular}

Table IV presents the electrical performances of the proposed circuit (with and without DGS) and some recent microstrip diplexers proposed in literature. It can be clearly observed that the proposed circuit is very small compared to other circuits operating at the same center frequencies. In addition, this microstrip diplexer is characterized by low insertion loss, good rejection, and acceptable isolation between the Rx and the Tx channels. 
In brief, this article proposes a simple design approach to achieve a compact microstrip diplexer with low insertion loss and high rejection. The novelty that offers this work is the ability to determine easily the resonant frequency of the modified $\mathrm{H}$-shaped resonators. Contrary to many circuits that use high order filters to achieve high rejection and better isolation, this paper proposes low order band pass filters with high rejection and good electrical performances. In fact, adjusting the dimensions and the position of each resonator can control easily the location of the spurious frequencies and the stop band.

The use of two modified $\mathrm{H}$-shaped resonators represents an interesting alternative to design compact diplexer with remarkable frequency response. Moreover, the proposed LC equivalent model is very attractive since it will be very useful to study the behavior of the circuit without changing its geometrical parameters, which will save more time in the design phase. Furthermore, the introduction of the DGS technique can control the operating frequencies and enhance the electrical performances of the first circuit without changing its dimensions. All these features show the originality and the novelty introduced in this paper.

\section{CONCLUSION}

In this paper a new topology of miniaturized microstrip band-pass filters with a good rejection level has been proposed. Based on modified H-shaped resonators, the overall size of the circuit can be reduced without any significant degradation of the electrical performances. By using this new topology two band-pass filters operating at $1.575 \mathrm{GHz}$ and $2.4 \mathrm{GHz}$ have been designed. Using these filters a compact microstrip diplexer with good performances has also been designed and simulated. Parametric studies have been achieved for different geometrical parameters of the Rx band-pass filter.

The proposed equivalent LC model can simplify the design of any structure using the H-shaped resonators. This new approach provides a simple method to achieve a miniature band-pass filter with wide stop band. The simulated frequency responses have demonstrated that the diplexer has interesting characteristics and performances with an insertion loss lower than $2 \mathrm{~dB}$ and a high isolation between the two channels better than $21 \mathrm{~dB}$. Besides, the proposed diplexer shows several transmission zeros beside the pass bands which enhance the selectivity of the BPFs. In addition, the proposed diplexer with cross-slots in its ground plane has good electrical performances which makes it an interesting circuit to operate for the GPS applications.

\section{REFERENCES}

[1] D. M. Pozar, Microwave Engineering, John Wiley \& Sons 1998.

[2] R. Levy, "Design considerations for lumped-element microwave filters," Microwave J., vol. 31, pp. 183-192, Feb. 1988.

[3] D. Zhang, G.-C. Liang, C. F. Shih, Z. H. Lu and M. E. Johansson, "A 19-pole cellular bandpass filter using 75mm diameter high-temperature superconducting film," IEEE Microwave and Guided-Wave Letters, 5, 11, 1995, $405-407$.

[4] Andrew J., Slobodnik, Thomas L., Szabo and Kenneth R., Laker, "Miniature Surface Acoustic wave Filter," Proc. IEEE, 67(1), 129 - 146, 1979.

[5] R. Azadegan, and K. Sarabandi, "Miniature High-Q Double-Spiral Slot-Line Resonator Filters," IEEE Transactions on Microwave Theory and Techniques, vol. 52, no. 5, MAY 2004. 
[6] J. Xiao, S. Ma, and Y. Li , "A novel H-shaped microstrip resonator and its design to filter using defected ground structure", Proceedings of the Conference on High Density Microsystem Design and Packaging and Component Failure Analysis, p. 1-4, 2005

[7] S. T. G. Bezerra and M. T. de Melo, "Microstrip Diplexer for GSM and UMTS Integration Using Ended Stub Resonators", Proceedings of the IEEE International Microwave and Optoelectronics Conference 2007, p. 954-958, 2007.

[8] H. A. Cabral, S. T. G. Bezerra, and M. T. de Melo, "A novel duplexer for UMTS applications based on a cross-coupled filter,'Microwave and Optical Technology Letters, Vol. 52, No. 12, December 2010.

[9] L.Bousbia,M.Mabrouk, A,Ghazel, "Study and Modeling of T and L shaped resonators for UWB band pass filter," EuroCon, Zagreb, Croatia. July-2013.

[10] S.V. Al-Din Makki, A.Ahmadi, S.Majidifar, "Sharp Response Microstrip LPF using Folded Stepped Impedance Open Stubs,"' Radioengineeging, Vol. 22, No. 1, April 2013.

[11] S. Amiri, N. Khajavi, M. Khajavi, "Design of Compact Filters with Narrow Band-pass and Wide stop-Band by OpenStub \& T-shaped Microstrip Resonators and Defected ground Structure (DGS),'’ Proceeding of the 2014 International Conference on communications, Signal Processing and Computers.

[12] Jia-Sheng Hong, Microstrip Filters for RF/Microwave Applications. John Wiley \& Sons, Inc. 2011.

[13] Skaik, Talal. "Synthesis of coupled resonator circuits with multiple outputs using coupling matrix optimization," Diss. University of Birmingham, 2011.

[14] Wahab, Norfishah Ab, Mohd Salleh, Mohd Khairul, Khanfar, Sameh Khamfar M. "Synthesis of a single side access ring resonator for higher order band pass filters," Progress In Electromagnetics Research Letters, 2013, Vol. 38, p. 137150 .

[15] Zakaria, Noor Zareena, BABA, N. H., et Salleh, MK Mohd. “'Top-coupled parallel-cascaded ring filter with transmission zeros," Science and Social Research (CSSR), 2010 International Conference on. IEEE, 2010. p. 10101012.

[16] Wang, R., Xu, J., Wang, M. Y., \& Dong, Y. L. “'Synthesis of microwave resonator diplexers using linear frequency transformation and optimization," Progress In Electromagnetics Research, Vol. 124, p. 441-455, 2012.

[17] Velidi, V. K., Prabhakaran, U., Subramanyam, A. V. G., Sivareddy, D., \& Srinivasan, V. V. “'Design of compact microstrip diplexer with high selectivity,' In Signal Processing and Communications (SPCOM), 2012 International Conference on (pp. 1-4). IEEE.

[18] Chen, C. F., T. Y. Huang, C. P. Chou, and R. B. Wu, "Microstrip diplexers design with common resonator sections for compact size, but high isolation," IEEE Trans. Microw. Theory Tech., Vol. 54, 1945-1952, 2006.

[19] http://www.home.agilent.com

[20] http://www.cst.com

[21] D.Ahn, J.S.Seok, C.S .Kim, Y.Qian, and I.Itoh, “'A design of low-pass filter using the novel microstrip defected ground structure,"' IEEE trans. Microwave Theory Tech., vol. 52, no.3, pp.86-93, Jan.2001.

[22] lal Shahu, B., Chattoraj, N., Pal, S., \& Upadhyay, D. K. “'A Compact UWB Bandpass Filter using Hybrid Fractal Shaped DGS. Journal of Microwaves," Optoelectronics and Electromagnetic Applications (JMOe), Vol. 16, No.1, 3849, 2016.

[23] Parui, S. K., \& Das, S. "Modeling of split-ring type defected ground structure and its filtering applications," Journal of Microwaves, Optoelectronics and Electromagnetic Applications (JMOe), Vol.8, No.1, 6-12, 2009.

[24] Boutejdar, A., Omar, A., Al Sharkawy, M., \& Darwish, A. “A simple transformation of improved WLAN band pass to low pass filter using defected ground structure (DGS), defected microstrip structure (DMS) and multilayertechnique," Journal of Microwaves, Optoelectronics and Electromagnetic Applications, Vol.12, No.1, 111-130. 2013.

[25] J.S. Yun, G. Y.Kim, J.S. Lim, J. S. Park, D. Ahn, K.W. Kang, and J.B. Lim, “'A design of novel coupled line band-pass filter by using using defected ground structure,’ IEEE MTT-S Int. Microw. Symp. Digest, pp.327-330, 2000.

[26] C.S. Kim, J.S. Lim, J. H. Kim, and D. Ahn, "A design of miniaturized 2-pole band pass filter by using using slot and hair-pin line,’’ IEEE MTT-S Int.Microw. Symp. Digest, pp.1983-1986, 2006.

[27] Chinig, A., Zbitou, J., Errkik, A., El Abdellaoui, L., Tajmouati, A., Latrach, M., \& Tribak, A. “A novel design of microstrip diplexer using triangular loop resonators." International Journal of Microwave and Optical Technology, Vol 1, No 10, Jan, 2015.

[28] Chinig, A., Errkik, A., Tajmouati, A., Bennis, H., Zbitou, J., \& Latrach, M. “The design of new structures of planar diplexers using microstrip resonators." Handbook of Research on Advanced Trends in Microwave and Communication Engineering, pp. 170-204, September, 2016.

[29] Chuang, M. L., \& Wu, M. T. "Microstrip diplexer design using common T-shaped resonator." Microwave and Wireless Components Letters, IEEE, Vol 11, No 21, pp. 583-585, October, 2011. 